A NEW HEAD LAMP, Devised by GLRERT CHUBB, M.B.,
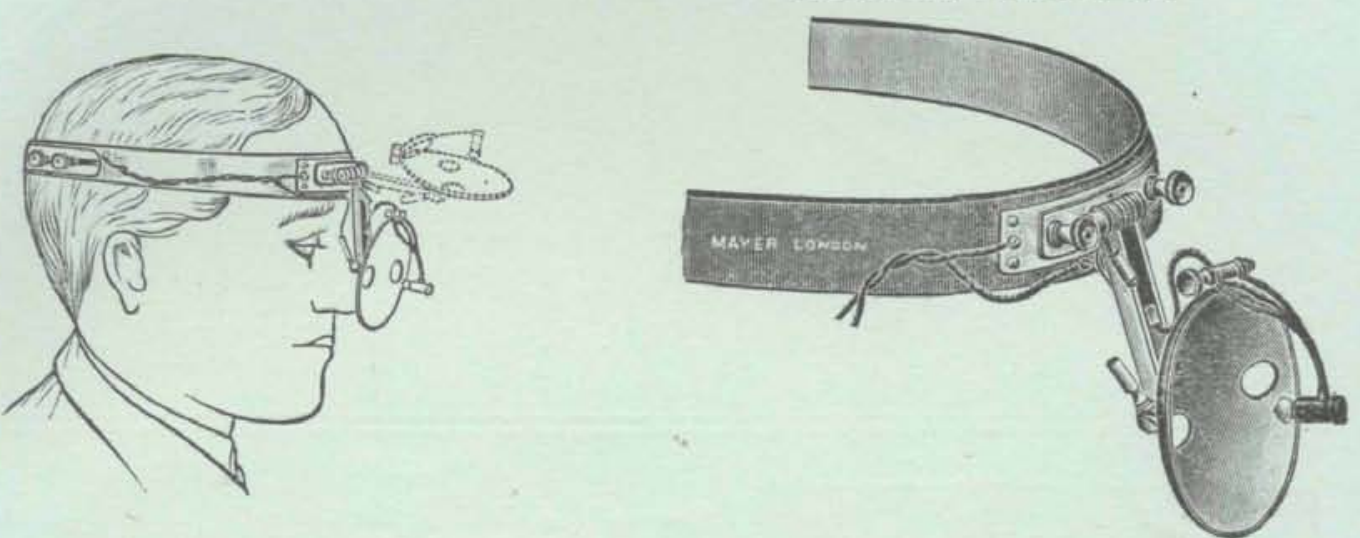

An improved lamp on the Klar principle; fitted with unbreakable mirror of speculum metal; easily adjusted and economical in use. (Vide Lancet, March 13 th, 1920.)

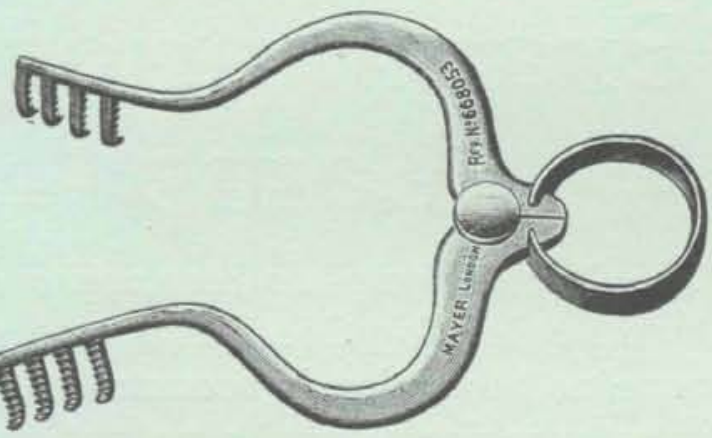

\title{
A MASTOID RETRACTOR
}

Designed by B. SEYMOUR JONES, F.R.C.S.,

Surgeon, Birmingham Ear and Throat Hospital.

A simple self-retaining spring retractor; easily placed in position and removed and not liable to slip when in use.

\section{A TONGUE HOLDER \& DEPRESSOR for Tonsillectomy.}

Suggested by JAMES DONELAN, Ch.M., M.B.

When removing the tonsils by dissection this tongue forceps has been found useful. The points are inserted trans. versely and well back in the dorsum of the tongue, which is depressed so as to give a good view and free the respi. ratory passages.

Particulars on application to

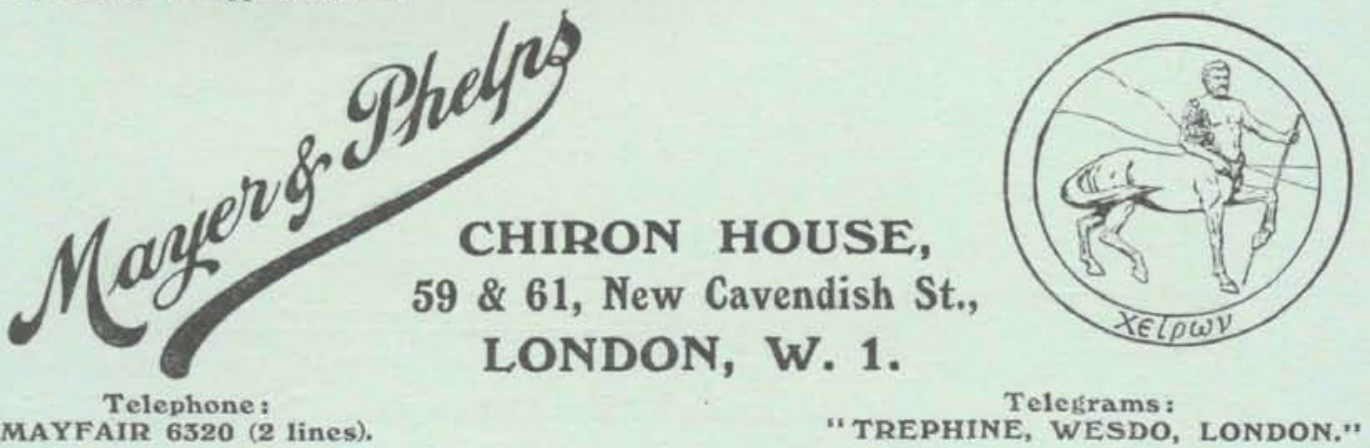



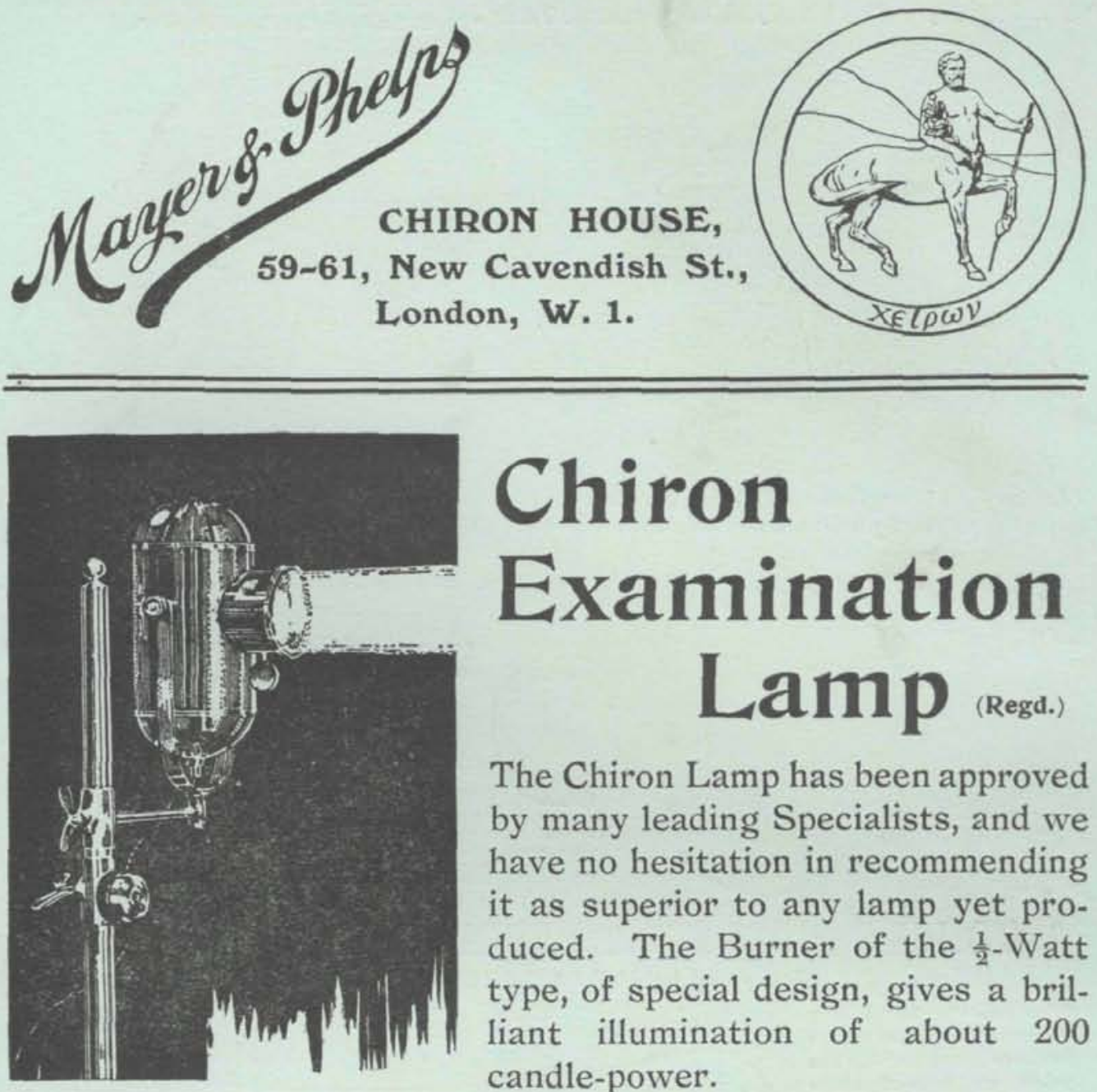

The Chiron Lamp has been approved by many leading Specialists, and we have no hesitation in recommending it as superior to any lamp yet produced. The Burner of the $\frac{1}{2}$-Watt type, of special design, gives a brilliant illumination of about 200 candle-power.

\section{TONSIL PASTE APPLICATOR.}

Devised by IRWIN MOORE, M.B., C.M.Edin., Surgeon to the Throat Hospital, Gelden Square.

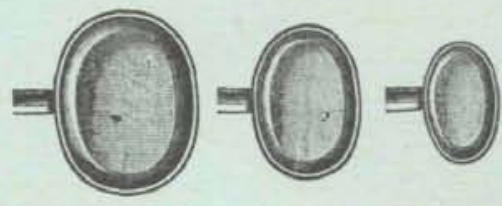

Vide "The Treatment of Enlarged or Diseased Tonsils in Cases where Surgical Procedures are Contra-indicated" (Fournal of Laryngology, October, 1919). 